\title{
ATP is released from nerve terminals and from activated muscle fibres on stimulation of the rat phrenic nerve
}

\author{
D.A. Santos ${ }^{\mathrm{a}}$, Audrey I. Salgado ${ }^{\mathrm{a}, *}$, Rodrigo A. Cunha ${ }^{\mathrm{b}}$ \\ ${ }^{a}$ Department Physiology and Biophysics, ICB - University of Federal Minas Gerais, Av. Antonio Carlos 6627, 31270-010 Belo Horizonte, \\ Minas Gerais, Brazil \\ ${ }^{\mathrm{b}}$ Center for Neurosciences of Coimbra, Institute of Biochemistry, Faculty of Medicine, University of Coimbra, $3000-504$ Coimbra, Portugal
}

Received 26 September 2002; received in revised form 3 December 2002; accepted 5 December 2002

\begin{abstract}
Nerve stimulation increases the concentration of ATP in the synaptic cleft, which can act as a neurotransmitter or as a presynaptic neuromodulator. Using the luciferin-luciferase assay, we observed that the extracellular concentration of ATP increased by $11-26 \mathrm{nM}$ over a basal concentration of $6 \mathrm{nM}$, in a frequency dependent manner $(1-5 \mathrm{~Hz})$, in the adult rat phrenic nerve-hemidiaphragm preparation. This ATP release depends on nerve activity since it was abolished by tetrodotoxin $(1 \mu \mathrm{M})$ and is strictly dependent on the presence of extracellular calcium. However, more than half of this nerve-evoked release of ATP is derived from activated muscle fibres since the selective postsynaptic nicotinic receptor antagonist, $\alpha$-bungarotoxin $(1 \mu \mathrm{M})$, inhibited by over $60 \%$ the evoked release of ATP. The presently observed post-synaptic release of ATP together with the previously reported lack of post-synaptic effects of ATP and to the ability of ATP to act as a presynaptic modulator open the possibility that ATP may behave as a retrograde messenger at this neuromuscular junction.

(C) 2002 Elsevier Science Ireland Ltd. All rights reserved.
\end{abstract}

Keywords: ATP; Release; Neuromuscular junction; Post-synaptic; Presynaptic

In both peripheral and central synapses, it is now recognised that the synaptic levels of ATP increase according to neuronal activity and that this extracellular synaptic ATP can act as a neurotransmitter or co-transmitter or as a presynaptic neuromodulator (reviewed in ref. [4]). In central nervous system (CNS) synapses like in the hippocampus, ATP can act as a neurotransmitter $[10,11]$ and the release of ATP is enriched in presynaptic preparations (cf. [3,6]). In contrast, at motor nerve endings, albeit the extracellular levels of ATP are also increased on stimulation of nerve afferents $[16,17,19]$, there seems to be a considerably larger contribution of post-synaptically released adenine nucleotides [5,19]. And interestingly, at neuromuscular junctions, ATP seems to be essentially devoid of direct post-synaptic actions (reviewed in ref. [8]), acting mainly as a presynaptic neuromodulator, either directly activating ATP (P2) receptors $[7,15]$ or acting via adenosine receptors upon its extracellular catabolism into adenosine [2,14,16]. Also, whereas the release of ATP from CNS preparations decays

\footnotetext{
* Corresponding author. Tel.: + 31-3499-2935; fax: + 31-3499-2924.

E-mail address: ivanenko@mono.icb.ufmg.br (A.I. Salgado).
}

during stimulation at lower frequencies [6], the release of adenine nucleotides and of ATP seems to be sustained at similar frequencies of stimulation at neuromuscular junctions $[5,19]$.

We now investigated the pattern of ATP release at the rat innervated hemidiaphragm using different frequencies of motor nerve stimulation to determine if ATP release decreases on motor nerve stimulation and tested the effect of D-tubocurarine and $\alpha$-bungarotoxin, which block nerveevoked twitch contraction, to evaluate the respective contribution of nerve and muscle fibres for ATP release.

The experimental protocol of ATP release from rat innervated hemidiaphragm preparations (8 $\mathrm{mm}$ width) evoked by phrenic nerve stimulation was as previously described [15], with minor modifications. Preparations were obtained from male Wistar rats 6 weeks old (about $130 \mathrm{~g}$ weight), after anesthesia under halothane atmosphere. After dissection, the preparations were mounted in $2 \mathrm{ml}$ chambers, with direct oxygenation $\left(95 \% \mathrm{O}_{2}\right.$ and $\left.5 \% \mathrm{CO}_{2}\right)$, kept at $37^{\circ} \mathrm{C}$, and superfused ( $3 \mathrm{ml} / \mathrm{min}$ ) with Tyrode solution (also continuously gassed) containing (mM): $\mathrm{NaCl}(137.0), \mathrm{KCl}$ (2.7), $\mathrm{CaCl}_{2}$ (1.8), $\mathrm{MgCl}_{2}$ (1.0), $\mathrm{NaH}_{2} \mathrm{PO}_{4}(0.4), \mathrm{NaHCO}_{3}$ 
(11.9), and glucose (11.2), pH 7.4. After a 30 min recovery period, the superfusion was stopped. Bath samples $(1.5 \mathrm{ml})$ were collected every $3 \mathrm{~min}$ by completely emptying and refilling the organ bath with the solution in use.

Two 3 min stimulation periods were applied (supramaximal square pulses with $15 \mathrm{~V}$ amplitude and $40 \mathrm{~ms}$ duration), using different frequencies $(1,3$ or $5 \mathrm{~Hz}$ ), at 12 min $\left(S_{1}\right)$ and at $39 \min \left(S_{2}\right)$ after starting sample collection (zero time). The evoked ATP release was calculated by subtraction of the basal concentration from the total concentration upon electrical stimulation. Test drugs (or different superfusion media) were added $15 \mathrm{~min}$ before $S_{2}$, and were present up to the end of the experiments. The change in the ratio between the evoked ATP released during the two stimulation periods $\left(\mathrm{S}_{2} / \mathrm{S}_{1}\right)$ relative to that observed in control situations (in the absence of test drugs, i.e. with control medium) was taken as a measure of the effect of the tested drugs (tetrodotoxin, D-tubocurarine and $\alpha$-bungarotoxin from Sigma).

ATP released from the preparations was assayed using the luciferin-luciferase technique, as previously described [6]. Briefly, $100 \mu \mathrm{l}$ aliquots of the bath samples were added to $100 \mu$ l of ATP assay mix (Sigma, containing firefly luciferase $0.33 \mathrm{mg}$, luciferin $0.83 \mathrm{mg}, \mathrm{MgSO}_{4} 6 \mathrm{mg}$, EDTA $2 \mathrm{mg}$, dithiothreitol $0.08 \mathrm{mg}$, bovine serum albumin $5 \mathrm{mg}$, Tricine $45 \mathrm{mg}$, reconstituted in $5 \mathrm{ml}$ of sterile water) and the luminescence was measured in a BioOrbit 1250 luminometer for $15 \mathrm{~s}$. Before the experiments a standard calibration curve was prepared (ATP concentrations between $10^{-9}$ and $10^{-12} \mathrm{M}$ ), and the levels of ATP in the bath samples were calculated from a linear double log fitting. The Tyrode solution without or with tested drugs was assayed for background ATP content. The increase in the bath concentration of ATP caused by electrical field stimulation (evoked release) was calculated by subtracting the basal concentration measured during the pre-stimulation period from the concentration of ATP during the stimulation period.

The results were evaluated by one-way analysis of variance followed by Dunnett's test (multiple comparisons), or Student's $t$-test (pairwise comparisons). $P \leq 0.05$ were considered statistically significant. All data were expressed as mean \pm SEM.

The basal concentration of extracellular ATP in rat innervated hemidiaphragm preparations was $6.31 \pm 0.51$ $\mathrm{nM}(n=21)$ and remained nearly constant during the time of sample collection. As shown in Fig. 1A, electrical stimulation of the phrenic nerve caused a marked increase in the extracellular levels of ATP. When stimulated for $3 \mathrm{~min}$ at $1 \mathrm{~Hz}$, the evoked release of ATP was $11.2 \pm 0.7 \mathrm{nM}$ $(n=6)$. A second identical stimulation period (S2) delivered $24 \mathrm{~min}$ after the first stimulation period caused a release of ATP similar $(P>0.05)$ to that released in the first stimulation period, with an $\mathrm{S} 2 / \mathrm{S} 1$ ratio of $1.02 \pm 0.12$ $(n=6)$. When we tested higher frequencies of nerve stimulation, we found that ATP was released in a frequency
A
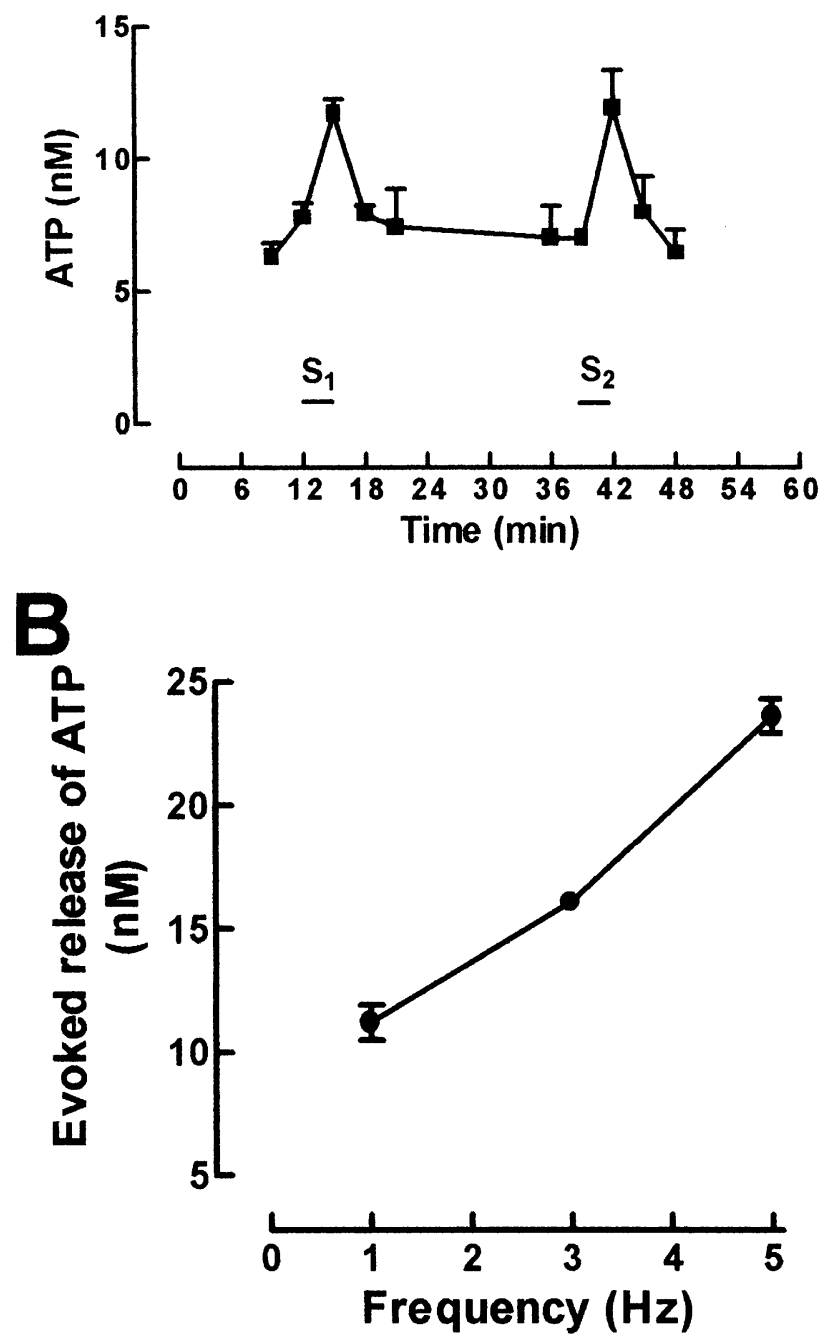

Fig. 1. Nerve stimulation triggers an evoked release of ATP that is frequency-dependent. In $A$ is shown a time course of ATP release, quantified in the effluent with the luciferin-luciferase assay, upon application of electrical stimulation through the phrenic nerve trunk (40 $\mathrm{V}, 40 \mathrm{~ms}, 1 \mathrm{~Hz}$ for $3 \mathrm{~min}) 12 \mathrm{~min}\left(\mathrm{~S}_{1}\right)$ and $39 \mathrm{~min}\left(\mathrm{~S}_{2}\right)$ after starting sample collection, as indicated by the bars above the abscissa. The data are mean \pm SEM of six experiments. Panel $B$ presents the effect of increasing frequencies of nerve stimulation on the evoked release of ATP, calculated as the subtraction of the basal bath concentration from the total release of ATP quantified on nerve stimulation. The results are mean \pm SEM of six experiments at each frequency of stimulation. ${ }^{*} P<0.05$.

dependent manner (Fig. 1B). In fact, stimulation at $3 \mathrm{~Hz}$ for 3 min caused a release of ATP of $16.1 \pm 0.4 \mathrm{nM}(n=6)$ and stimulation at $5 \mathrm{~Hz}$ also for 3 min caused a release of ATP of $23.6 \pm 0.7 \mathrm{nM}(n=6)$. Again, when two periods of stimulation were applied $24 \mathrm{~min}$ apart, the S2/S1 ratio was near unit at both of these tested frequencies $(1.04 \pm 0.06$, $n=6$, at $3 \mathrm{~Hz}$ and $1.10 \pm 0.13$ at $5 \mathrm{~Hz}, n=6)$.

To further exclude the occurrence of a run-down of ATP release during stimulation, as was observed to occur at $5 \mathrm{~Hz}$ stimulation in rat hippocampal slices [6], we tested the effect of increasing stimulation frequencies in the same 
Table 1

Increasing frequencies of nerve stimulation cause an increase release of ATP $^{\mathrm{a}}$

\begin{tabular}{llllll}
\hline S1 $(\mathrm{Hz})$ & S2 $(\mathrm{Hz})$ & ATP $(\mathrm{nM})$ & & S2/S1 & $n$ \\
\cline { 3 - 4 } & & $\mathrm{S} 1$ & $\mathrm{~S} 2$ & \\
\hline & & $11.2 \pm 0.7$ & $15.9 \pm 0.7$ & $1.41 \pm 0.10$ & 6 \\
1 & 3 & $12.4 \pm 0.6$ & $26.3 \pm 1.1$ & $2.12 \pm 0.13$ & 6 \\
3 & 5 & $16.1 \pm 0.4$ & $21.4 \pm 2.4$ & $1.33 \pm 0.15$ & 6
\end{tabular}

a The same rat innervated hemidiaphragm preparation was stimulated first at a lower frequency during $3 \mathrm{~min}$ (S1) and $24 \mathrm{~min}$ later at a higher frequency also during $3 \mathrm{~min}(\mathrm{~S} 2)$, which resulted in $\mathrm{S} 2 / \mathrm{S} 1$ ratio always greater $(P<0.05)$ than unit, whereas when the preparations were stimulated at the same frequency during $\mathrm{S} 1$ and $\mathrm{S} 2$, the $\mathrm{S} 2 / \mathrm{S} 1$ ration was always near unit ( $n$ is the number of experiments).

preparation. As illustrated in Table 1, there was an increased release of ATP in S2, whenever the stimulation frequency tested in $\mathrm{S} 2$ was greater than that used in $\mathrm{S} 1$, whereas the $\mathrm{S} 2 /$ S1 ration was near unit when using any of the tested stimulation frequencies $(1,3$ or $5 \mathrm{~Hz})$ both in $\mathrm{S} 1$ and in $\mathrm{S} 2$.

The nerve-evoked release of ATP was dependent on neuronal activity since it was essentially abolished in the presence of $1 \mu \mathrm{M}$ tetrodotoxin (tested at 1 and $5 \mathrm{~Hz}, n=3$ for each situation). As occurs for the vesicular release of neurotransmitters, the nerve-evoked release of ATP was also calcium-dependent since omission of calcium in the superfusion solution during S2 essentially abolished the evoked release of ATP (tested at 1 and $5 \mathrm{~Hz} n=3$ for each situation). To distinguish whether the release of ATP occurs from the nerve terminals or from the activated muscle fibres, we prevented nerve-evoked muscle fibre activation with Dtubocurarine, which, at a concentration of $1 \mu \mathrm{M}$, blocks nerve-evoked twitch contraction [12]. As documented in Table 2, D-tubocurarine ( $1 \mu \mathrm{M})$ caused a decrease of over $50 \%$ in the nerve-evoked release of ATP, which was similar $(\mathrm{P}>0.05)$ with the different tested stimulation frequencies (Table 2). However, since D-tubocurarine also affects the nerve-evoked release of acetylcholine by interfering with presynaptic facilitatory nicotinic acetylcholine receptors [1], we tested the effect of another nicotinic receptor antagonist, $\alpha$-bungarotoxin, that selectively antagonises post-synaptic nicotinic acetylcholine receptors in the rat

Table 2

The nicotinic receptor antagonist, D-tubocurarine, in a concentration that blocks nerve-evoked twitch contraction $(1 \mu \mathrm{M})$, added $15 \mathrm{~min}$ before the second stimulation period $(\mathrm{S} 2)$, significantly attenuated $(P<0.05)$ the nerve-evoked release of ATP ( $n$ is the number of experiments)

\begin{tabular}{|c|c|c|c|c|c|c|}
\hline \multirow{2}{*}{$\begin{array}{l}\mathrm{S} 1 \\
(\mathrm{~Hz})\end{array}$} & \multirow{2}{*}{$\begin{array}{l}\mathrm{S} 2 \\
(\mathrm{~Hz})\end{array}$} & \multicolumn{2}{|l|}{ ATP (nM) } & \multirow[t]{2}{*}{$\mathrm{S} 2 / \mathrm{S} 1$} & \multirow[t]{2}{*}{$\%$ inhibition } & \multirow[t]{2}{*}{$n$} \\
\hline & & $\mathrm{S} 1$ & $\mathrm{~S} 2$ & & & \\
\hline 1 & 1 & $13.7 \pm 0.6$ & $6.3 \pm 0.5$ & $0.46 \pm 0.04$ & $54 \pm 7$ & 6 \\
\hline 1 & 3 & $13.6 \pm 0.6$ & $6.9 \pm 0.9$ & $0.50 \pm 0.03$ & $50 \pm 8$ & 6 \\
\hline 3 & 3 & $21.2 \pm 3.5$ & $5.8 \pm 0.7$ & $0.27 \pm 0.05$ & $73 \pm 8$ & 6 \\
\hline 3 & 5 & $21.2 \pm 3.5$ & $10.1 \pm 1.2$ & $0.48 \pm 0.05$ & $52 \pm 7$ & 6 \\
\hline
\end{tabular}

Table 3

The nicotinic receptor antagonist, $\alpha$-bungarotoxin, in a concentration that blocks nerve-evoked twitch contraction $(1 \mu \mathrm{M})$, added $15 \mathrm{~min}$ before the second stimulation period $(\mathrm{S} 2)$, significantly attenuated $(P<0.05)$ the nerve-evoked release of ATP ( $n$ is the number of experiments)

\begin{tabular}{lllllll}
\hline S1 (Hz) & S2 $(\mathrm{Hz})$ & ATP $(\mathrm{nM})$ & \multicolumn{2}{l}{ S2/S1 } & \% inhibition & $n$ \\
\cline { 3 - 4 } & & S1 & & & \\
& & & & & & \\
1 & 1 & $13.7 \pm 0.6$ & $2.9 \pm 0.4$ & $0.21 \pm 0.02$ & $79 \pm 7$ & 6 \\
1 & 3 & $13.7 \pm 0.6$ & $3.4 \pm 0.3$ & $0.25 \pm 0.03$ & $75 \pm 8$ & 6 \\
3 & 3 & $21.2 \pm 3.5$ & $6.3 \pm 0.8$ & $0.30 \pm 0.02$ & $70 \pm 8$ & 6 \\
3 & 5 & $21.2 \pm 3.5$ & $8.2 \pm 0.5$ & $0.39 \pm 0.04$ & $61 \pm 7$ & 6 \\
\hline
\end{tabular}

innervated hemidiaphragm (Correia-de-Sá, personal communication from submitted work). As documented in Table $3, \alpha$-bungarotoxin $(1 \mu \mathrm{M})$ caused a decrease of over $60 \%$ in the nerve-evoked release of ATP, which was similar $(P>0.05)$ with the different tested stimulation frequencies (Table 3).

Several works using different neuromuscular junctions from different species and different stimulation patterns have concluded that nerve stimulation triggers the release of ATP $[16,17,19]$. There is some debate as to whether this released ATP is originated from nerve terminals [16] or from activated muscle fibres [19]. In the present work, we have found that the release of ATP is frequency-dependent and is partially reduced upon blockade of nicotinic receptors. From our data, it appears that around $60 \%$ of released ATP might be derived from the activated muscle fibres, based on the inhibition caused by D-tubocurarine and $\alpha$-bungarotoxin. This is in good agreement with what was found at the mouse hemidiaphragm [19].

Another conclusion from the present work is that the release of ATP seems to be sustained during the stimulation of the phrenic nerve at the tested frequencies, in contrast to what is observed in hippocampal preparations [6] and to a minor extend in innervated smooth muscle preparations (e.g. ref. [18]). In fact, there is a clear frequency-dependent increase in the nerve-evoked release of ATP and the consecutive stimulation of the same preparations with increasing frequencies of stimulation triggers the release of increasing amounts of ATP. It is also interesting to note that the absolute amounts of ATP detected in the bath of stimulated hemidiaphragm preparations are larger than these recorded in hippocampal or cortical preparations [6, 13]. This larger release of ATP at neuromuscular synapses might be a consequence of the significant contribution of activated muscle fibres for the nerve-evoked ATP release. In fact, we now confirmed in the rat innervated hemidiaphragm using different frequencies of nerve stimulation that more than half of the released ATP might be derived from activated muscle fibres, based on the ability of Dtubocurarine and $\alpha$-bungarotoxin to attenuated by over $50 \%$ the nerve-evoked ATP release. This scenario is different from that found in CNS preparations, where blockade of excitatory neurotransmission failed to signifi- 
cantly modify the evoked release of ATP [20] and where it is observed that there is an enrichment of the specific evoked ATP release when using purified nerve terminals (cf. refs. [3,6]).

But the relevant question from the functional point of view is what might be the role of extracellular ATP in the control of neuromuscular transmission. Most reports have concluded that exogenously added ATP, up to micromolar concentrations, is devoid of effects on mature muscle fibres (reviewed in ref. [8]). In fact, in mature neuromuscular junctions, the only consensual role of extracellular ATP is to presynaptically control the release of acetylcholine [2,7, 14-16]. However, whereas some reports concluded that adenine nucleotides have to be extracellularly converted into adenosine to modulate neurotransmitter release $[2,14$, 16], others have provided evidences that support a direct presynaptic modulatory of ATP acting through P2 receptors $[7,15]$. But, irrespective of whether extracellular ATP might control the release of acetylcholine at the neuromuscular junction via P1 or P2 receptors, the presently observed significant contribution of the activated muscle fibres for the accumulation of extracellular ATP opens the new possibility that ATP may essentially fulfil a role of retrograde messenger at these synapses, as previously proposed to occur in the Torpedo electric organ [9].

\section{Acknowledgements}

We thank M.F. Pereira for helping in the experiments on the effect of tetrodotoxin on nerve-evoked ATP release, carried out at the Lab. Neurosciences (Fac. Medicine of Lisbon), using the luminometer kindly supplied by Prof. C. Saldanha. This work was supported by FAPEMIG and FCT (SAU/14014/1998). DA Santos was supported by CNPq.

\section{References}

[1] P. Correia-de-Sá, J.A. Ribeiro, Tonic adenosine $A_{2 A}$ receptor activation modulates nicotinic autoreceptor function at the rat neuromuscular junction, Eur. J. Pharmacol. 271 (1994) 349-355.

[2] P. Correia-de-Sá, M.A. Timóteo, J.A. Ribeiro, Presynaptic A inhibitory/ $\mathrm{A}_{2 \mathrm{~A}}$ facilitatory adenosine receptor activation balance depends on motor nerve stimulation paradigm at the rat hemidiaphragm, J. Neurophysiol. 76 (1996) 3910-3919.

[3] R.A. Cunha, T. Almeida, J.A. Ribeiro, Modification by arachidonic acid of extracellular adenosine metabolism and neuromodulatory action in the rat hippocampus, J. Biol. Chem. 275 (2000) 37572-37581.

[4] R.A. Cunha, J.A. Ribeiro, ATP as a presynaptic modulator, Life Sci. 68 (2000) 119-137.

[5] R.A. Cunha, A.M. Sebastião, Adenosine and adenine nucleotides are independently released from both the nerve terminals and the muscle fibres upon electrical stimulation of the innervated skeletal muscle of the frog, Pflügers Arch. Eur. J. Physiol. 424 (1993) 503-510.

[6] R.A. Cunha, E.S. Vizi, J.A. Ribeiro, A.M. Sebastião, Preferential release of ATP and its extracellular catabolism as a source of adenosine upon high- but not low-frequency stimulation of rat hippocampal slices, J. Neurochem. 67 (1996) 2180-2187.

[7] R.A. Giniatullin, E.M. Sokolova, ATP and adenosine inhibit transmitter release at the frog neuromuscular junction through distinct presynaptic receptors, Br. J. Pharmacol. 124 (1998) 839-844.

[8] R.H. Henning, Purinoceptors in neuromuscular transmission, Pharmacol. Ther. 74 (1997) 115-128.

[9] M. Israel, B. Lesbats, R. Manaranche, F.M. Meunier, P. Franchon, Retrograde inhibition of transmitter release by ATP, J. Neurochem. 34 (1980) 923-932.

[10] M. Mori, C. Heuss, B.H. Gähwiler, U. Gerber, Fast synaptic transmission mediated by $\mathrm{P} 2 \mathrm{X}$ receptors in CA3 pyramidal cells of rat hippocampal slice cultures, J. Physiol. (Lond.) 535 (2001) $115-123$.

[11] Y. Pankratov, E. Castro, M.T. Miras-Portugal, O. Krishtal, A purinergic component of the excitatory postsynaptic current mediated by $\mathrm{P} 2 \mathrm{X}$ receptors in the CA1 neurons of the rat hippocampus, Eur. J. Neurosci. 10 (1998) 3898-3902.

[12] W.D.M. Paton, D.R. Waud, Neuromuscular blocking agents, Br. J. Anaesth. 34 (1962) 251-259.

[13] P. Potter, T.D. White, Release of adenosine $5^{\prime}$-triphosphate from synaptosomes from different regions of rat brain, Neuroscience 5 (1980) 1351-1356.

[14] J.A. Ribeiro, J. Walker, The effects of adenosine triphosphate and adenosine diphosphate on transmission at the rat and frog neuromuscular junctions, Br. J. Pharmacol. 54 (1975) 213-218.

[15] A.I. Salgado, R.A. Cunha, J.A. Ribeiro, Facilitation by $\mathrm{P}_{2}$ receptor activation of acetylcholine release from rat motor nerve terminals: interaction with presynaptic nicotinic receptors, Brain Res. 877 (2000) $245-250$

[16] E.M. Silinsky, J.K. Hirsh, T.J. Searl, R.S. Redman, M. Watanabe, Quantal ATP release from motor nerve endings and its role in neurally mediated depression, Prog. Brain Res. 120 (1999) 145-158.

[17] D.O. Smith, Sources of adenosine released during neuromuscular transmission in the rat, J. Physiol. (Lond.) 432 (1991) 343-354.

[18] P. Sneddon, T.D. Westfall, L.D. Todorov, S. Mihaylova-Todorova, D.P. Westfall, C. Kennedy, Modulation of purinergic neurotransmission, Prog. Brain Res. 120 (1999) 11-20.

[19] E. Vizi, K. Nitahara, K. Sato, B. Sperlágh, Stimulation-dependent release, breakdown, and action of endogenous ATP in mouse hemidiaphragm preparation: the possible role of ATP in neuromuscular transmission, J. Auton. Nervous Syst. 81 (2000) 278-284.

[20] A. Wieraszko, G. Goldsmith, T.N. Seyfried, Stimulation-dependent release of adenosine triphosphate from hippocampal slices, Brain Res. 485 (1989) 244-250. 